\title{
HIV Infection Testing and Service Delivery of One Accredited Treatment Center in Cameroon
}

\author{
Serge Bruno Ebong ${ }^{1}$, Calixte Ida Penda ${ }^{2,3,6}$, Juste Patient Mbébi Enoné ${ }^{\text {, }}$ \\ Patricia Epee Eboumbou ${ }^{2,6}$, Madeleine Mbangue ${ }^{4}$, Samuel Honore Mandengue ${ }^{1}$, \\ Carole Else Eboumbou Moukoko ${ }^{5,6,7, *}$ \\ ${ }^{1}$ Laboratory of Physiology and Animal Biology, Faculty of Sciences, University of Douala, Douala, Cameroon \\ ${ }^{2}$ Department of Clinical Sciences, Faculty of Medicine and Pharmaceutical Sciences, University of Douala, Douala, Cameroon \\ ${ }^{3}$ Accredited HIV Care Center of Laquintinie Hospital of Douala, Douala, Cameroon \\ ${ }^{4}$ Biological Laboratory, Laquintinie Hospital of Douala, Douala, Cameroon \\ ${ }^{5}$ Biological Sciences Department, Faculty of Medicine and Pharmaceutical Sciences, University of Douala, Douala, Cameroon \\ ${ }^{6}$ Laboratory of Parasitology, Mycology and Virology, Postgraduate Training Unit for Health Sciences, Postgraduate School for Pure and \\ Applied Sciences, University of Douala, Douala, Cameroon \\ ${ }^{7}$ Center Pasteur of Cameroon, Yaounde, Cameroon
}

Email address:

ebongserge@yahoo.fr (S. B. Ebong), idapenda@yahoo.fr (C. I. Penda), patientmbebi@yahoo.fr (J. P. M. Enoné), patepebm1@gmail.com (P. E. Eboumbou), madombangue@yahoo.fr (M. Mbangue), shmandengue@yahoo.fr (S. H. Mandengue), elsecarole@yahoo.fr (C. E. E. Moukoko)

${ }^{*}$ Corresponding author

\section{To cite this article:}

Serge Bruno Ebong, Calixte Ida Penda, Juste Patient Mbébi Enoné, Patricia Epee Eboumbou, Madeleine Mbangue, Samuel Honore Mandengue, Carole Else Eboumbou Moukoko. HIV Infection Testing and Service Delivery of One Accredited Treatment Center in Cameroon. International Journal of HIV/AIDS Prevention, Education and Behavioural Science. Vol. 6, No. 2, 2020, pp. 53-61. doi: 10.11648/j.ijhpebs.20200602.14

Received: September 2, 2020; Accepted: October 6, 2020; Published: October 13, 2020

\begin{abstract}
Effectiveness of Anonymous and free Voluntary Counseling and Testing (AVCT) Centers in the HIV prevention and care can be threatened by a low use of its service delivery, especially in developing countries. This study was designed to obtain reliable data on the current state of the quality of the services and, evaluate the factors that are associated with use of one Accredited HIV/AIDS Treatment Center (AHTC). A cross-sectional and prospective study was conducted among adults attending the AHTC of the Douala Laquintinie Hospital (DLH), Cameroon. Anonymous interviews including both open and closed ended questions were conducted in participants selected by convenience sampling. Descriptive and logistic regression analyses were performed using StataSE11 software (version 11 SE) in data analysis. Overall 80 (64\%) of 125 adult volunteers for HIV testing reported that the reception at AHTC was excellent and 69.6\% (80/115) of those who underwent the pre-test and among them, $49.6 \%$ were satisfied with the pre-test. Less than half of the participants were explained the merits of HIV testing. The interview was conducted in a confidential framework in $60 \%$ of those who underwent the pre-test and, $41.7 \%$ explained the merits of HIV testing. Among the 10 evaluated minimal items that the provider should have addressed, less than 6 items were done in $66.9 \%$ of the participants and between 9 and 10 items for $11.3 \%$. Informed consent agreement was obtained in $89.60 \%$ of volunteers. Knowledge of HIV status was more reported among men than women who reported more requesting the HIV testing for prevention strategies for an exclusive sexual relation $(\mathrm{p}=0.038)$. The prevalence of HIV infection was $25.6 \%$ and, primary education remained significantly associated with higher risk of HIV infection in multivariate analysis $(\mathrm{OR}=0.11$; IC95\% $=0.015-0.72 ; p=0.022$ ). These results highlight the important of the appropriate sensibilization for the responsible implementation of the pretest counseling steps by health care providers in the AHTC of the DLH.
\end{abstract}

Keywords: HIV, Anonymous and Free Voluntary Counseling and Testing, Quality of the Services, Cameroon 


\section{Introduction}

The latest national data on the HIV/AIDS epidemic in Cameroon dates back to 2004 and shows a persistent and widespread endemic situation in the country, and young women remain the most affected, particularly in the 20-39 age groups $[1,2]$. Although the prevalence of HIV/AIDS decreased in 2016 , from $4.3 \%$ in 2011 to an estimated $3.8 \%$ in 2016, the number of new infections has steadily increased, from an average of 32,000 new infections in 2010 , to 36,000 in 2016; an increase of $5 \%$ [3, 4]. The number of AIDS-related deaths decreased by $13 \%$ from 29,000 in 2010 to 27000 in 2016 [3, 4]. In this context, Cameroon has adhered to the strategic obectives 90-90-90 of United Nations program on HIV/AIDS (UNAIDS), which aims to increase HIV testing to $90 \%$, achieve ART coverage of $90 \%$ and $90 \%$ of people on antiretroviral therapy (ART) achieve viral suppression by 2020 , but that is not realistic [5]. If the country continues to expand and strengthen its National Program to Fight HIV/AIDS (NPFAIDS), the prevalence rate could remain below 6\% until 2020 [6]. In this struggle, Anonymous and free Voluntary Counseling and Testing (AVCT) Centers play a crucial role as HIV prevention is also intensified by increasing access to voluntary HIV counseling and testing services. In Cameroon, as in many countries, these AVCTs allow the identification of people living with HIV (PLHIV) and offer free treatment for HIV positive patients, care and support through a confidential dialogue between the individual and a counselor. They are therefore an indispensable tool in the fight against HIV transmission and contribute to the prevention policy by helping consultants to define a personal strategy for HIV/AIDS. They must therefore be accessible to anyone who wishes to know their status. According to their conditions of access and their distribution in the metropolitan cities of Cameroon, there is 22 Accredited HIV/AIDS Treatment Center (AHTC) per region and around 60 Take Care HIV Units (TCHU) in the 10 regions of Cameroon (Far-North, North, Adamoua, Littoral, Center, South, East, West, North-West and SouthWest). HIV testing activity in the AVCTs shows significant regional and local disparities [7-9]. These disparities are partly explained by the situation of the epidemic in each region and are also reflected in the overall screening activity as reported by the analytical laboratories but also in the quality of the care [10-12]. Qualitatively, majority of the population attending the AVCTs are young people under 30 years of age and women $[10,12]$. The difference over time between men and women in the proportion of positive screenings, particularly among consultants under 40 years of age, where women are know the most affected $[10,11]$. Studies suggest several barriers to the use of AVCTs as ignorance, poverty, stigma, discrimination, inadequate number of AVCTs, the knowledge of their service providers, their organization and their operation [7, 11-14]. We have been unable to identify in the literature any population based studies on feeling of the population towards service provided by the AVCT and the factors which could influence the use of this centers by Cameroonian population. Within in this context, this study was designed to provide reliable information within the framework set out by the comprehensive PLHIV management service offering from the patient's perspective attending the AHTC of Douala Laquintinie Hospital (DLH) located in the Littoral region of Cameroon and, where HIV prevalence was estimated at $4.6 \%$ in 2011 , higher than the national prevalence of $4.3 \%$ [3]. These results may help to develop better strategies for the planning, implementation, monitoring and evaluation of epidemic prevention programs, from the people affected by this disease to an operational application of evidence among the general population.

\section{Materials and Experiments}

\subsection{Study Design and Population}

A cross-sectional study was conducted for seven months (August 2014 to February 2015) among adults and, attending the AHTC of DLH located at the Douala $1^{\text {st }}$ district of the Littoral region in Douala, Cameroun. With an estimated average annual population growth rate of $5 \%$ the last 30 years and a current population of approximately 2,500,000 inhabitants (officially 1,931,977), Douala is therefore the largest city in Cameroon with an estimated annual average population growth rate of $5 \%$ the last 30 years. The DLH houses an AHTC (91\% of participants are adults vs $9 \%$ of children and adolescents) and a virology laboratory to evaluate HIV infections. In 2014, the DLH monitored about 5.000 peoples living with HIV, including about 4.500 on antiretroviral therapy.

We used a convenience sampling a non-probability sampling applicable in the study when the members of the population are convenient to sample. For limit the selection and information biases, participants were enrolled systematically and consecutively.

The survey's target population was all people of 17 years old and over with unknown HIV status and who presented to the AHTC of DLH for request a voluntary HIV testing. The voluntaries were asked verbally when they came to the AHTC whether they would like to HIV testing or not and if it is the fiisrt time except for blood dons. If the answer was "no", they will be excluded. If yes, they will be approached to participate in the study.

The administered questionnaire was conducted following a 1-week pre-test among 10 peoples outside of the study area to assess understanding and acceptability of study participants. The questions were formulated so as not to influence the participants in their answers. After the pre-test, the modifications had been made on the ambiguous questions. The questionnaire was first prepared in French and translated into English to ensure consistency and comparability. The questionnaire was administered independently on the same 
day by two Master degree students to estimate interinterviewer reproducibility. Participants did not receive any information sheets on the AHTC service offerings during these two interviews to minimize the risk of a change in response.

Information sheets on HIV/AIDS infection were provided to all consultants after the interview and completing the questionnaire, with the emphasis on the mode of transmission, the protection strategies, the consequences of HIV infection and the need to HIV testing for rapid management that allow the patient to live a normal life for several years. This sheet allowed having information on what is HIV/AIDS? What is the test? Why it is done and its confidentiality? What is the purpose of counseling and the various preventive strategies?

This study was conducted in accordance with ethics directives related to research on humans in Cameroon. The Institutional Review Board of the University of Douala approved the study and administrative authorization from DLH was obtained. Before to registration and administration of the questionnaire, subjects were informed of the purpose and process of the survey (background, objectives, methodology, study constraints, data confidentiality, and rights to withdraw from the study) and, a signed informed consent was obtained from all participants who agreed to participate in the study in accordance with the Helsinki Declaration (2000). Participation was voluntary, anonymous and without compensation.

\subsection{Study Questionnaire}

The questionnaire explored several axes and they were open-ended (OEIQ) and closed-ended (CEIQ) interview questions, including a single answer, and multiple choices questions (Figure 1).

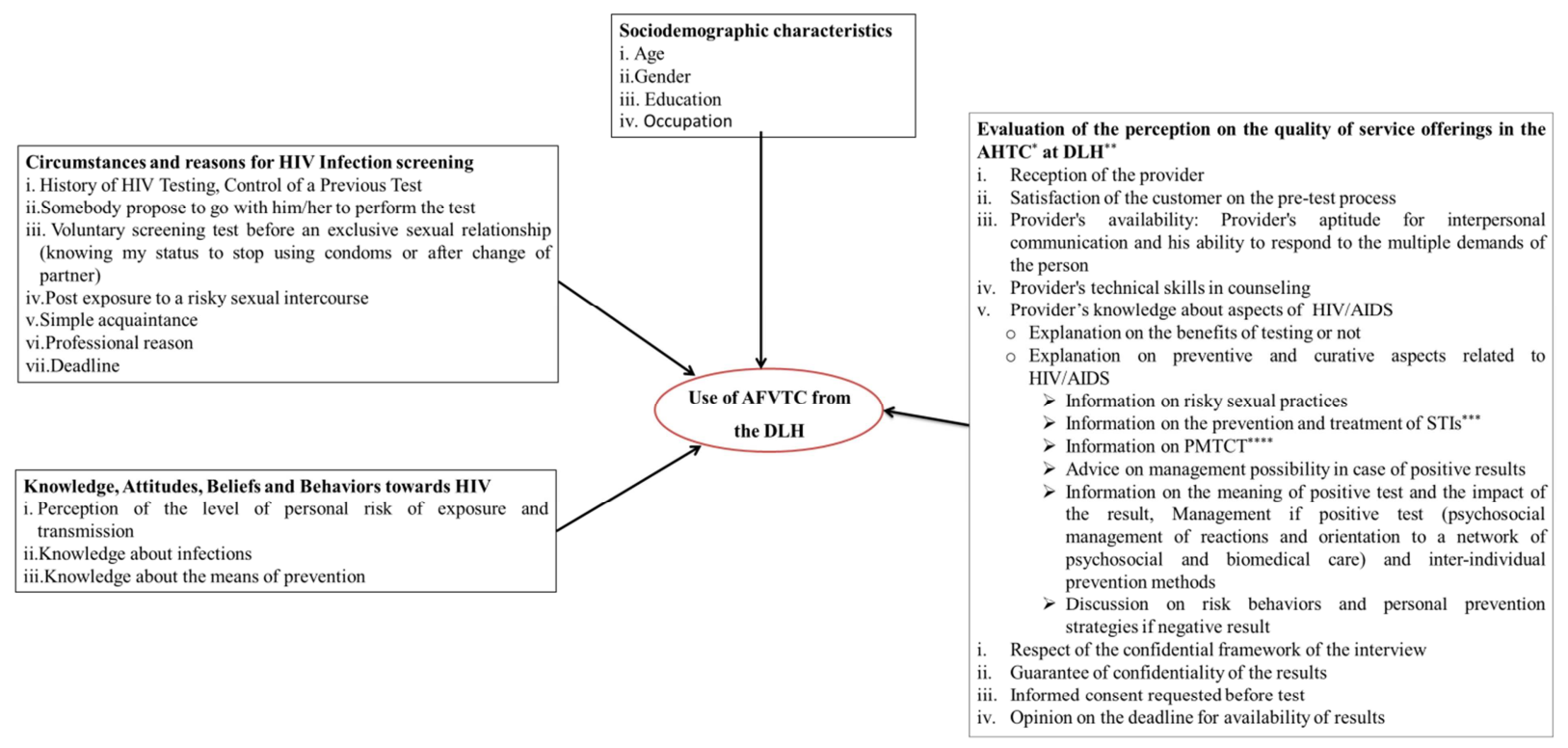

Note, ", AHTC: Accredited HIV/AIDS Treatment Center; "', DLH: Douala Laquintinie Hospital, "*, STIs: Sexual transmutable infection; "**, PMTCT: prevention mother to child transmission

Figure 1. Flow chart on the evaluation of factors that may limit the use of AHTC of DLH.

Data collection sheets were used to collect data on: (i) socio-demographic characteristics, (ii) circumstances and reasons for HIV testing, (iii) knowledge, attitudes, beliefs and behaviors to HIV/AIDS and, (iv) perception on the quality of service offerings in the AHTC of DLH. The Communication for Behavioral Change (CBC) variable was evaluated to determine the different ways people heard about HIV, that led them to adopt new behaviors or to do the screening: interpersonal communication (IPC) between an individual and another individual, that is, between the claimant and the subject and mass communication (MC) which consists of exchanging information about the AHTC with a group of people at varying distances through educational talks, radio or television broadcasts or theatre.

\subsection{Statistical Analysis}

Categorical variables were expressed as frequencies, whereas numerical variables (Age) were presented as means and Standard deviation (SD), as data is normally distribution. Comparing proportions, we used Chi-square test or Fisher'exact test. Numerical values were compared using a parametric test, the Student-test. Only the variables significant in the univariate model were analyzed in a multivariate logistic regression model and taking into account all confounding factors. All statistical analyzes were performed using Stata software (version $11 \mathrm{SE}$ ) and, only p-values $<0.05$ were considered significant in all analyses.

\section{Results}

\subsection{Characteristics of Participants in Population Survey}

A total of 155 participants had been asked verbally when they came to the AHTC of DLH whether they would like to 
do HIV test, among them 30 participants were excluded due to a health check-up requested. Finaly, we enrolled 125 out of 155 participants who came for HIV testing and agreed to participate. Overall, the male/female sex ratio amongst all selected participants was $1 / 1.4(53 / 72)$, and the mean age was not significantly different between male and female (Table 1).

Table 1. Characteristics by gender of participants attending the AHTC of DLH.

\begin{tabular}{|c|c|c|c|c|}
\hline \multirow{2}{*}{ Variables } & \multirow{2}{*}{$\begin{array}{l}\text { Female } \\
72(57.6) \\
\end{array}$} & \multirow{2}{*}{$\begin{array}{l}\text { Male } \\
53(42.4)\end{array}$} & \multirow{2}{*}{$\begin{array}{l}\text { Total } \\
125 \\
\end{array}$} & \multirow[b]{2}{*}{$\mathbf{p}$} \\
\hline & & & & \\
\hline Age mean (SD), years & $35.0(10.9)$ & $38.5(12.9)$ & $36.5(11.9)$ & 0.116 \\
\hline \multicolumn{5}{|l|}{ School-education } \\
\hline Primary & $16(22.2)$ & $10(18.9)$ & $26(20.8)$ & \multirow{3}{*}{0,075} \\
\hline Secondary & $41(56.9)$ & $30(56.6)$ & $71(56.8)$ & \\
\hline University & $15(20.8)$ & $13(24.5)$ & $28(22.4)$ & \\
\hline \multicolumn{5}{|l|}{ Marital status } \\
\hline Widowed/Divorced & $2(2.8)$ & $2(3.8)$ & $4(3.2)$ & \multirow[t]{2}{*}{0.630} \\
\hline Married/Concubine & $30(41.7)$ & $26(40.0)$ & $56(44.8)$ & \\
\hline \multicolumn{5}{|l|}{ Occupation } \\
\hline Unemployed & $31(43.1)$ & $19(35.8)$ & $50(40.0)$ & \multirow{4}{*}{0,657} \\
\hline Public/ Private sector employee & $7(9.7)$ & $7(1.2)$ & $14(11.2)$ & \\
\hline Informal sector & $19(26.4)$ & $12(22.6)$ & $31(24.8)$ & \\
\hline Executing Agent/ Mastering & $15(20.8)$ & $15(28.3)$ & $30(24.0)$ & \\
\hline
\end{tabular}

Data are number and/or proportion (\%), unless otherwise indicated.

The majority $(80.0 \%)$ of the participants was over 25 years of age and those under the 20 years represented only $5.6 \%$ of the population. The most represented age group was 26-36 years old with $32.8 \%$ of participants. More than half $(56.8 \%)$ of the study population had a secondary-education, and overall, no difference was observed for educational level between men and women $(\mathrm{p}=0.075)$. For women as for men, the majority of participants were unemployed and unmarried and the frequency of this distribution of occupational activity or marital status was not significantly different. Among unemployed customer, $20 \%$ and $42 \%$ were between $18-25$ years old and between 26-35 years old respectively. Just over a third $(30.5 \%$ for women and $41.5 \%$ for men) of participants reported has a occupation. When comparing those who had an occupation, the majority of women had a an informal activity ( $26.4 \%$ vs $22.6 \%$ for men) whereas, men were the executing agent or mastering ( $28.3 \%$ vs $20.8 \%$ for women) and the frequency of this distribution was not significantly different.

More than half consultants $(82,65.6 \%)$ came from the Douala $1^{\text {st }}(31,24.8 \%)$ and $3^{\text {rd }}(51,40.8 \%)$ district.

\subsection{Circumstances, Reasons and HIV Infection Testing}

The HIV testing was personal for all participants who came alone. As shown in Table 2, overall, the main reason for testing was the knowledge of HIV status for $76.8 \%$ of participants.

Table 2. Prevalence of HIV infection, circumstances and reasons for HIV testing.

\begin{tabular}{lllll}
\hline \multirow{2}{*}{ Variables } & Female & Male & Total & p \\
\cline { 2 - 4 } & $\mathbf{7 2 ( 5 7 . 6 )}$ & $\mathbf{5 3 ( 4 2 . 4 )}$ & $\mathbf{1 2 5}$ & Reference \\
\hline Circumstances of screening & & & & \\
HIV status simple knowledge & $51(70.8)$ & $45(84.9)$ & $96(76.8)$ & 0.236 \\
Check of a Previous test $_{\text {Prevention strategy }}^{*}$ & $13(18.1)$ & $1(13.2)$ & $20(16.0)$ & 0.038 \\
Exposure to a risky $^{* *}$ & $8(11.1)$ & $0(0.0)$ & $9(7.2)$ & $/$ \\
Professional reason & $0(0.0)$ & $0(0.0)$ & $/$ & $/$ \\
HIV infection & $0(0.0)$ & $11(34.4)$ & $32(25.6)$ & 0.196 \\
\hline
\end{tabular}

Data are number and/or proportion (\%). *, HIV testing before an exclusive sexual relationship (knowing status to stop using condoms or after change of partner); **, Post exposure to a risky sexual intercourse.

Knowledge of HIV status was more reported among men than women who reported more requesting the HIV testing for prevention strategies for an exclusive sexual relation $(\mathrm{p}=0.038)$. No significant differences by age group in the reasons for HIV testing. The most infected patients were observed among the 2635 year-old group $(32.8 \%)$ and, any group was not more infected than another. The prevalence of HIV infection was $25.6 \%$ and, a significantly difference was observed according to the school-education $(\mathrm{p}=0.031)$. This prevalence was significantly lower among participants with higher education compared to participants with primary education $(10.7 \%$ vs $42.3 \%$, OR $=0.17$, IC95\%: 0.03-0.8, $\mathrm{p}=0.018$ ). Among men participants, most of HIV positive were inactive $(63.6 \%$ vs $36.4 \%$ for worker, $\mathrm{OR}=4.37$, IC95\%: 1.07-17.7, $\mathrm{p}=0.039)$. Overall, significant difference was observed for HIV status between "single" and "Married/Concubine" status ( $\mathrm{p}=0.033)$, but this remained significantly different only when comparing the different subgroups of person with unmarried and the married/concubine person $(66.1 \%$ vs $33.9 \%$ for married/concubine person, $\mathrm{OR}=2.52$, IC95\%: 1.1-5.9; $\mathrm{p}=0.033$ ). After multivariate analysis, 
primary education remained significantly associated with higher risk of HIV infection $(\mathrm{OR}=0.11$; IC95\% $=0.015-0.72 ; \mathrm{p}=0.022)$.

\subsection{Information, Attitudes, Beliefs and Behavioral Risk of HIV Infection}

According to this survey, most $(99.2 \%, 98.6 \%$ of women and $100 \%$ of men) of participants were able to define AIDS, to name the pathogen and to indicate the main modes of HIV transmission. More than half consultants $(52.8 \%)$ reported to have received information on HIV/AIDS through mass communication (MC) (Table 3).

Table 3. Source of Information on HIV/AIDS and determinants associated with risk behavior and risk factors for HIV infection.

\begin{tabular}{|c|c|c|c|c|}
\hline \multirow{2}{*}{ Variables } & Female & Male & Total & \multirow[b]{2}{*}{$\mathbf{p}$} \\
\hline & $72(57.6)$ & $53(42.4)$ & 125 & \\
\hline \multicolumn{5}{|c|}{ IEC approachs on knowledge of infection ${ }^{*}$} \\
\hline $\mathrm{IPC}^{* *}$ & $1(1.4)$ & $2(3.8)$ & $3(2.4)$ & Reference \\
\hline $\mathrm{MC}^{* * *}$ & $42(58.7)$ & $24(45.3)$ & $66(52.8)$ & 0.316 \\
\hline $\mathrm{IPC} / \mathrm{MC}$ & $29(40.3)$ & $27(50.9)$ & $56(44.8)$ & 0.487 \\
\hline Execution of a preventive action plan & $55(76.4)$ & $44(83.0)$ & $99(79.2)$ & 0.250 \\
\hline \multicolumn{5}{|l|}{ Sexual behavior } \\
\hline Single partner & $33(45.8)$ & $21(39.6)$ & $54(43.2)$ & 0.832 \\
\hline Multiple partners & $16(22.3)$ & $15(28.3)$ & $31(24.8)$ & 0.639 \\
\hline Unprotected sex & $19 / 49(38.8)$ & $18 / 36(50.0)$ & $37 / 85(43.5)$ & 0.377 \\
\hline Alcohol consumption & $57(79.2)$ & $46(86.8)$ & $103(82.4)$ & 0.193 \\
\hline Previous transfusion & $6(8.3)$ & $3(5.7)$ & $9(7.2)$ & 0.419 \\
\hline Intravenous drug use & $00(0.0)$ & $00(0.0)$ & $00(0.0)$ & l \\
\hline Presence of tattoos/piercing & $19(26.4)$ & $13(24.5)$ & $32(25.6)$ & 0.491 \\
\hline
\end{tabular}

Data are number and/or proportion (\%). *, IEC, Information Education and Communication; ${ }^{* *}$, IPC Interpersonal communication; ${ }^{* * *}$, MC: mass communication.

Interpersonal communication (IPC) and MC were the most communication approach reported by men, whereas, women reported more the $\mathrm{MC}$ and the frequency of this distribution was not significantly different. All consultants were able to name at least one preventive action plan (condoms, no sharing of risk materials). Among them, one fifth (20.8\%) did not have a preventive action plan, of which women $(65.4 \%)$ reported that they use fewer preventive measures than men $(34.6 \%)$, but the difference was not statistically significant. Sexual orientation and determinants associated with risk behavior and risk factors for HIV infection were analyzed and, one third of the participants $(32.0 \%)$ reported having no sexual relations with a partner in the past six months. All participants who reported having sexual activity said that it was exclusively heterosexual, $36.5 \%$ and $7.1 \%$ reported having multiple partners and sex relation with prostitutes in the past six months respectively (Table 2). During sexual relations with a partner in the past six months, $43.5 \%$ of participants reported a protected sexual activity. Almost participants (6/7) who engaged in sexual activity with prostitutes reported more use of protective measures and the difference was statistically significant $(\mathrm{OR}=8.9$; IC95\%: 1.0$27.0 ; p=0.049)$. The distribution of quality and quantity of partners in the last 6 months prior to the study did not differ by sex or age. Over $82.4 \%$ reported not drinking alcohol all the time and, the consumption did not vary by gender or age. The number of people who received transfusion and, got tattoo in the past 6 months was $9(7.2 \%)$ and $25(25.6 \%)$ respectively. None of the participants admitted to taking of intravenous drugs.

\subsection{Quality of the Service Offerings and Quality Perception Assessment of Service Provider at the AHTC of DLH}

Overall, $80(64 \%)$ participants reported that the welcome at the AHTC was welcoming and 115 (92.0\%) participants received counseling before HIV testing (Table 4). Among the participants who underwent the pre-test, 69.6\% (80/115) found the reception of the AHTC excellent and, to the question "Were you satisfied with your interview prior to the HIV pre-testing?", only 57 (49.6\%) answered "yes". Overall, men who underwent the pre-test were more satisfied than women but this difference was not statistically significant $(52.2 \%$ vs $47.8 \%$ for women, $\mathrm{p}=0.295)$. Majority of participants $(38.6 \%)$ who reported satisfaction during counseling was between 26-35 years old followed by participants with $36-45$ years old (24.6\%). Only $54.8 \%$ of participants reported a good availability of AHTC staff and $36.5 \%$ felt that the provider was proficient in counseling technical skills.

Thirty nine (33.9\%) participants who underwent the pretesting felt AHTC staff had good explanations on the different aspects related to HIV/AIDS. The level of service delivery on aspects related to HIV/AIDS has been evaluated by assessing through the issues that the provider should address, the advice it must provide and the information it must give before the HIV test implementation (Table 4).

Table 4. Assessment of the quality of service offerings in the AHTC at DLH*.

\begin{tabular}{|c|c|c|c|c|}
\hline \multirow{2}{*}{ Variables } & Female & Male & Total & \multirow[b]{2}{*}{$\mathbf{p}$} \\
\hline & $72(57.6)$ & $53(42.4)$ & 125 & \\
\hline Excellent reception of the provider & $46(63.9)$ & $34(64.2)$ & $80(64.0)$ & 0.488 \\
\hline
\end{tabular}




\begin{tabular}{|c|c|c|c|c|}
\hline \multirow{2}{*}{ Variables } & Female & Male & Total & \multirow[b]{2}{*}{$\mathbf{p}$} \\
\hline & $72(57.6)$ & $53(42.4)$ & 125 & \\
\hline Pre-test performed & $69(95.8)$ & $46(86.8)$ & $115(92.0)$ & 0.067 \\
\hline Satisfied with pre-test process & $33(47.8)$ & $24(52.2)$ & $57 / 115(49.6)$ & 0.395 \\
\hline Good opinion of participant on provider's technical skills in counseling & $22(31.9)$ & $20(43.5)$ & $42 / 115(36.5)$ & 0.143 \\
\hline Received explanations about the different aspects related to HIV/AIDS & $35(50.7)$ & $20(43.5)$ & $55 / 115(47.8)$ & 0.284 \\
\hline $\begin{array}{l}\text { Good opinion of participant on explanations given about the different aspects related to } \\
\text { HIV/AIDS }\end{array}$ & $21(60.0)$ & $18(90.0)$ & $39(70.9)$ & 0.017 \\
\hline Mean number of items addressed $\left(I Q_{(25-75)}\right)^{* * * *}$ & $4.1(3-5)$ & $4.8(3-7)$ & $4.4(3-6)$ & 0.196 \\
\hline Information received on the benefits of testing or not & $28(80.0)$ & $20(100.0)$ & $48(87.3)$ & 0.033 \\
\hline Information received on risky sexual practices & $26(74.3)$ & $19(95.0)$ & $45(81.8)$ & 0.055 \\
\hline Information received on the prevention and treatment of STIS ${ }^{* *}$ & $24(68.6)$ & $16(80.0)$ & $40(72.7)$ & 0.278 \\
\hline Information received on $P M T C T^{* * *}$ & $17(48.6)$ & $14(70.0)$ & $31(56.4)$ & 0.103 \\
\hline Advice on management possibility in case of positive results & $17(48.6)$ & $10(50.0)$ & $27(49.1)$ & 0.570 \\
\hline $\begin{array}{l}\text { Information on the meaning of positive test and the impact of the result, Management if } \\
\text { positive test (psychosocial management of reactions and orientation to a network of } \\
\text { psychosocial and biomedical care) and inter-individual prevention methods }\end{array}$ & $21(60.0)$ & $9(45.0)$ & $30(54.5)$ & 0.214 \\
\hline Discussion on risk behaviors and personal prevention strategies if negative result & $11(31.4)$ & $8(40.0)$ & $19(34.5)$ & 0.361 \\
\hline Respect of the confidential framework of the interview by the provider & $41(59.4)$ & $28(60.9)$ & $69(60.0)$ & 0.517 \\
\hline Received information on guarantee of confidentiality of the results & $17(24.6)$ & $11(23.9)$ & $28(24.4)$ & 0.556 \\
\hline $\begin{array}{l}\text { Received information on need to have the Informed consent agreement before the test is } \\
\text { carried out }\end{array}$ & $66(96.7)$ & $46(100.0)$ & $112(97.4)$ & 0.212 \\
\hline \multicolumn{5}{|l|}{$\begin{array}{l}\text { carried out } \\
\text { Number of issues addressed, advice provided and information given during the pre-test }\end{array}$} \\
\hline Mean number issues addressed $\left(\mathrm{IQ}_{(25-75)}\right)^{* * * *}$ & $3.9(1-6)$ & $3.9(1-6)$ & $3.9(1-6)$ & 0.916 \\
\hline$[1-2]$ & $35(50.7)$ & $26(56.5)$ & $61(53.0)$ & Reference \\
\hline [3-5] & $11(15.9)$ & $5(10.9)$ & $16(13.9)$ & 0.298 \\
\hline$[6-8]$ & $17(24.6)$ & $8(17.4)$ & $25(21.7)$ & 0.252 \\
\hline$[9-10]$ & $6(8.7)$ & $7(15.2)$ & $13(11.3)$ & 0.331 \\
\hline Provider's availability & $36(52.2)$ & $27(58.7)$ & $63(54.8)$ & 0.310 \\
\hline \multicolumn{5}{|l|}{ Particpant's opinion on the deadline for availability of results } \\
\hline Short & $5(6.9)$ & $2(3.8)$ & $7(5.6)$ & Reference \\
\hline Long & $67(93.1)$ & $51(96.2)$ & $118(94.4)$ & 0.364 \\
\hline
\end{tabular}

Data are number and/or proportion (\%), unless otherwise indicated. ", AHTC at DLH: Accredited HIV/AIDS Treatment Center at the Douala Laquintinie Hospital, ${ }^{* *}$, STIs: Sexual transmitted infections; ${ }^{* * *}$, PMTCT: prevention mother to child transmission; ${ }^{* * * *}, \mathrm{IQ}_{(25-75)}$ : second and fourth InterQuartile (IQ) above the median.

Out of the seven items addressed, information provided to consultants focused on whether or not to the HIV testing is beneficial followed by information on risky sexual practices and on the prevention and treatment of sexual transmitted infections (STIs). These items were addressed to $47.8 \%$ of the participants and among them, more than 3 items were addressed in 2 out of 3 participants $(36 / 55,65.5 \%)$. Only 11 (20\%) participants reported that they had discussed the 7 items with center staff. The most discussed items were the advantages or not of HIV testing $(87.3 \%)$ more with male than female ( $80 \mathrm{u}$ vs $100 \%, \mathrm{p}=0.033$ ), the risky sexual practices $(81.8 \%)$ and, the prevention and treatment of STIs (72.7\%). The discussion on risk behaviors and personal prevention strategies if negative test was the least discussed item $(34.5 \%)$ with the participants during the counseling with 1 in 3 participants (Table 4 ).

Three out of 5 participants reported that the interview was conducted in a confidential framework and, to the question "were you told that the participant's prior informed consent agreement needed before carrying out any HIV testing?" 97.4\% of participants said yes (Table 4).

The mean number of the 10 items addressed for assessment the quality of service offerings in the AHTC at DLH among those who underwent the HIV testing was 3.9 (min-max: 1-10). In more than half of the participants, only two out of 10 items that the provider should have addressed were. The staff of the AHTC covered less than 6 items of the pre-test in $66.9 \%$ of participants and between 9 and 10 items in $11.3 \%$. The 10 items addressed only in $8(7 \%)$ participants. Fewer than $95 \%$ of participants estimated the deadline for results availability of 3 long days is long (Table 4).

\section{Discussion}

This study aimed to assess for the first time the practices of one AVCT center for the HIV prevention and care in Cameroon to evaluate the PLHIV management service offering by this unit. Furthermore, this epidemiological survey represents one first study on a point of view of people attending one AHTC. We conducted a questionnaire was administrated to people attending the AVCT center and various questions were raised by combining the results of the various studies [2, 4, 13-16].

Together, our data show an extremely low use of the services of the AHTC of the DLH during the 7 months of recruitment (2014-2015) with only 126 people attending the center for HIV testing whereas, a $5 \%$ increase in the infection was observed between 2010 and 2015 in Cameroun [3, 4].

Several obstacles to the use of AHTC services were reported, the socio-demographic characteristics and the knowledge on HIV/AIDS of people as factor than could limit the AVCT centers access [6, 11, 16-18]. In our study, 99.2\% 
of participants were able to define AIDS, to name the pathogen and to indicate the main modes of HIV transmission. The mean age of our study population (36.5 years) was higher than that found in the population of immigrants from sub-Saharan Africa (27.5 years) who attended the AVCT centers in France [16]. In this study, several AVCT centers ( 273 vs 1 in this study) were included which give a sample size significantly larger than ours (3119 vs 125). Our data show a predominance of women and elderly ( $83 \%$ are at least 25 years old) in overall population. Women attending the AHTC of the DLH were younger than men $(59.72 \%$ under 36 years old vs $43.40 \%$ for men). Considering that, a similar finding has previously been found and showing that the population attending the AVCT centers are young people under 30 years of age and women and, particularly among consultants under 40 years of age women are now the most affected [10-12, 16-18]. Of the infected people, $65.6 \%$ were women and the overall prevalence of HIV infection was $25.6 \%$ significantly higher than the national prevalence estimated at $6 \%$ this year and which, according to some estimates, would remain stable until 2020 [6]. This high prevalence could be linked to the high exposure of the study population infection risk as, 24.8 and $26.6 \%$ reported respectively, having multiple partners and presented tattoos/piercing. Another possible explanation for a greater use of AVCT centers by women compared to men is precisely the reasons for their use. Our study shows that, in addition to the motivations to want to know (or not) its HIV status mentioned by women and men in the same proportions, women also go to these centers for prevention strategies (HIV testing before a relationship exclusive sex) more than men (11.1\% vs $1.9 \%$ for men). For $76.8 \%$ of the participants, the first reason for the test was a simple knowledge of their status. In contrast to a previous study [16] wherein the first reason for the HIV testing was to stop using condoms with your sexual partner (24\%), we observed only $7.2 \%$ of participants reported to test for a prevention strategy (know their status to stop the use of condoms in a couple) for an exclusive sexual relationship or after a change of partner.

Other factors can have an impact on the use of AHTC services as, the methods of communication on people's knowledge of HIV/AIDS [6, 7, 11], Concerning the information, attitudes, beliefs and behavioral risk of HIV infection, most of participants $(99.2 \%)$ were able to define HIV/AIDS and correctly reported the main modes of HIV transmission and one fifth did not have a preventive action plan. The finding is consistent with previous report indicating that no association was found on risk perception and HIV testing according to gender and more than $80 \%$ of people who have risky sexual activity reported more use prevention methods [8, 16, 19]. Another studies reported a high prevalence (40 to $47.1 \%$ ) of consultants with a poor knowledge of mode of HIV transmission [7, 9] indicating that, the methods of communication can play a crucial role on the IEC.

Unprotected sex, intravenous drug use were reported in these studies as the most know of all HIV transmission's mode [7, 9]. Interestingly, participants in our study, as in others $[11,12]$, no one mentioned voluntary HIV testing as a means of prevention. MC was the primary communication approach through which participants reported receiving IEC on HIV/AIDS, the most commonly used means of communicating communication approach on HIV information reported in other studies [8, 15]. Stigmatization still present $[10,18]$ and the existence of high-cost ARV medical care for populations, as reported in some studies [13, 14] were others factors that could reduce the use of AHTC services. Considering this above, all consultants attended the AHTC of the DLH alone and most of them came far from their place of residence, as reported in others previous studies $[16,20,21]$.

A qualitative evaluation of the AHTC of the DLH was carried out to gather views on the services provided by this center and, the perceived effectiveness in relation to the different roles assigned to them. Knowledge of HIV status has been advocated as a prerequisite for access to support and care and increasingly as prevention measure in its own right and, voluntary counseling and testing (VCT) remains the most widely accepted approach for promoting knowledge of status and is efficient in improving access to health care [22]. In this context, AVCT Centers play important roles: i) it remains primarily a prevention and education activity because they help people to change their sexual behaviors to remain HIVnegative and help HIV- positive patients do not transmit infection to their sexual partner, ii) facilitate the early and adequate use of certain services such as care, family planning, psychological and social support, legal assistance and counseling to live in positive way and iii) it is also crucial for enabling women and their families to benefit from interventions to prevent mother-to-child transmission of HIV [2]. We observed that $64 \%$ of participants reported very good reception at the AHTC of the DLH, $92.0 \%$ of these received counseling before their HIV testing and, among them $46.6 \%$ reported satisfaction during counseling. The request for informed consent was asked to almost all of the participants (97.4\%) before carrying out the test but, the confidential framework for counseling was respected only to $60 \%$ of people. Of the 10 items analyzed and that the provider must address, the aspects related to HIV (47.8\%) were the least discussed item with the participants followed by information on confidentiality of the results $(24.4 \%)$. Few women received information about PMTCT, which may have consequences for preventive measures in particular in pregnant women tested positive. The lack of qualified personnel in developing countries which results in a low level of knowledge of i) the steps of counseling before HIV testing (on average 40\%), ii) the post-test counseling objectives (on average $31 \%$ ), iii) the qualities of a provider (on average 55\%), iv) the principles of an AHTC (on average 59\%) and, v) the sources of information and definition of the different means of communication (on average $60 \%$ give poor definitions) reported elsewhere [4-7, 23 ] could explain why only 2 of the 10 articles analyzed were addressed by staff and that, only $33 \%$ of those questioned believed that the service provider had a good grasp of 
"counseling" techniques found in our study. The below findings is consistent with the above findings and suggesting the quality of these service offerings can have an impact on the use of the AVCT centers $[6,7,11]$.

\section{Conclusion}

In conclusion, the above findings suggest that the how CVD staff conduct the pre-test was acceptable in some respects, but one participants out of three who underwent the pre-testing felt AHTC staff had good explanations on the different aspects related to HIV/AIDS. The level of service delivery on aspects related to HIV/AIDS has been evaluated by assessing through the issues that the provider should address, the advice it must provide and the information it must give before the HIV test implementation. The mean number of the 10 items (advices provided and informations given about HIV/AIDS) addressed for assessment the quality of service offerings in the AHTC at DLH among those who underwent the HIV testing was very low 3.9/10. Only two of the 10 items that the provider should have addressed were in more than half of the participants, and the 10 items was addressed only in $7 \%$ of participants. This study highlights the need to to step up efforts to increase providers' awareness of AHTC of the DLH, deepen their knowledge and create the right attitude towards AHTC through the large-scale dissemination of normative national documents.

\section{Availability of Data and Materials}

All data underlying the findings have been presented within the manuscript.

\section{Abbreviations}

AHTC: Accredited HIV/AIDS Treatment Center, ART: antiretroviral therapy (ART), AVCT: Anonymous and free Voluntary Counseling and Testing, CEIQ: closed-ended, DLH: Douala Laquintinie Hospital, CBC: Communication for Behavioral Change, IPC: interpersonal communication, MC: mass communication, OEIQ: open-ended, PLHIV: people living with HIV, STIs: sexual transmitted infections, TCHU: Take Care HIV Units.

\section{Consent for Publication}

Consent to publish has been obtained from all included persons in the study.

\section{Competing Interests}

The authors declare that they have no competing interests.

\section{Acknowledgements}

We are very grateful to the questionnaire respondents who agreed to participate in this study. We express our gratitude to the DLH AFVTC personel for their support and cooperation during the survey. Thanks to Pr Eboumbou Carole and Pr Ida Penda who reviewed and revised the manuscript for language editing. Statistical analysis and the interpretation of data were supported by International Society for Health Research and Training (ISRT-Health), a local Lecturer network.

\section{References}

[1] National AIDS Committee Ministry of Health (CNLS / MINSANTE). National Strategic Plan to Combat HIV, AIDS and STIs (2011-2015). Yaounde, Cameroon; 2010. Avalible at http://www.google.cm/?gwsrd=cr\&ei=QYpDU95FIsfxPKHog NAM $\# \mathrm{q}=\mathrm{CNLS}+$ rappport+EPP-

spectrum $+2010+$ au + cameroun. Accessed January 2019.

[2] United Nations AIDS (UNAIDS). The Impact of Voluntary Counseling and Testing: A Global Overview of Challenges and Challenges, Geneva; 2002. 101p. Available at http://www.google.cm/data.unaids.org/publications/ircpub02/jc580-vct_fr.pdf. Accessed April, 2019.

[3] Beogo T, Gaston E. Contribution to improving communication between caregivers and caregivers in the health area of Bittou, dissertation, ENSP, Department of Biology. 97p. 1997.

[4] Family Health International. HIV Testing Council in Africa, Strategic Framework. 15p. 2001.

[5] Bain LE, Nkoke C, Noubiap JJN. UNAIDS 90-90-90 targets to end the AIDS epidemic by 2020 are not realistic: comment on "can the UNAIDS 90-90-90 target be achieved? A systematic analysis of national HIV treatment cascades." BMJ Glob Health. 2017; 2: e000227.

[6] Some F. Factors Influencing Interpersonal Communication in Maternity Facilities in the Ouagadougou District 30 Health District, Graduation Thesis, NPHS. 102p. 2001.

[7] Yahaya LA, Jimoh AA, Balogun OR. Factors hindering acceptance of HIV/AIDS voluntary counseling and testing (VCT) among youth in Kwara State, Nigeria. Afr J Reprod Health. 2010; 14 (3): 159-164.

[8] Kaufman MR, Massey M, Tsang SW, Kamala B, Serlemitsos E, Lyles E et al. An assessment of HIV testing in Tanzania to inform future strategies and interventions. AIDS Care. 2018; 27 (2): $213-7$

[9] Traore F. Acceptability by parents of children hospitalized in pediatric settings in Bobo Dioulasso: screening for HIV infection, Doctoral thesis, UO. 1997; 13 p.

[10] Sawadogo JN. Voluntary HIV serological screening: knowledge and attitudes of young people in Kaya commune, final year thesis, NPHS. 2003; 105p.

[11] Zigani Z. Study of the factors explaining the low use of HIV VCT services in the city of Ouagadougou by the informal sector: the case of people engaged in small business, graduation thesis, NPHS. 2004; 100p.

[12] Rouamba G. Factors determining the low attendance of the HIV / AIDS voluntary testing center by women of childbearing age in the commune of Manga, graduation thesis, UO. 2006; 108p. 
[13] World health organization (WHO). Unified guidelines on the use of antiretrovirals for the treatment and prevention of HIV infection. Summarizes the main features and recommendations. 2013. Available at http://www.who.int/hiv/pub/guidelines/arv2013/15facts. Accessed December, 2019.

[14] Isseu D, Nkurunzizaii T, Sagoe-Mosesii C, Conomboii G, Ketselaii T. Prevention of mother-to-child transmission of HIV / AIDS in sub-Saharan Africa. Regional Office of the World Health Organization for the African Region. 2013; 2-12.

[15] Xiao Z, Li X, Lin D, Tam CC. Mass Media and HIV / AIDS Prevention among Female Sex Workers in Beijing, China. J. Health. Common. 2015; 7: 1-12.

[16] Levu S, Semaille C. Anonymous and free HIV testing. Profile of CDAG consultants in 2004 - Cross-sectional epidemiological survey. InVS. 2006; IVS0170_CDAG_301106.

[17] Gouëzel P. Anonymous and free HIV screening (CDAG), focus on the consultants, national survey in 2004. Institute for Public Health Surveillance, Saint-Maurice, France. 2009. French file. https://hal.univ-lorraine.fr/hal01733970/document.

[18] Kedote M. Analysis of the prevention program for mother-to- child transmission implementation in Benin. Doctoral thesis in Medicine, University of Montreal. 2012. 229p. French file. https://papyrus.bib.umontreal.ca/xmlui/bitstream/handle/1866/ 9223/Kedote_Marius_2012_these.pdf?sequence=7\&isAllowe $\mathrm{d}=\mathrm{y}$.

[19] Brouard C. Anonymous and free HIV testing consultations. National epidemiological survey. DESS thesis in statistics and methodology in biomedical research, University Paris XI, Institute of health monitoring. 2001; 102 p. French file. https://hal.univ-lorraine.fr/hal-01733970/document.

[20] Kayibanda C. Surveillance and risk factors associated with HIV in Rwanda. Doctoral thesis in epidemiology, Laval University, Quebec. 2011; 203p. French file. http://citeseerx.ist.psu.edu/viewdoc/download?doi=10.1.1.629 $.4016 \&$ rep $=$ rep $1 \&$ type $=$ pdf.

[21] Laraqui S, Laraqui O, Manar N, Ghailan T, Belabsir M, Deschamps F, et al. The assessment of seafarers' knowledge, attitudes and practices related to STI/HIV/AIDS in northern Morocco. Int Marit Health. 2017; 68 (1): 26-30.

[22] Mutanga JN, Raymond J, Towle MS. Institutionalizing provider-initiated HIV testing and counselling for children: an observational case study from Zambia. PLoS ONE. 2012; 7 ; e29656. 2012. 